\title{
The In Vitro Antimicrobial Effects of Lavandula angustifolia Essential Oil in Combination with Conventional Antimicrobial Agents
}

\author{
Stephanie de Rapper, ${ }^{1}$ Alvaro Viljoen, ${ }^{2,3}$ and Sandy van Vuuren ${ }^{1}$ \\ ${ }^{1}$ Department of Pharmacy and Pharmacology, Faculty of Health Sciences, University of the Witwatersrand, 7 York Road, \\ Parktown 2193, South Africa \\ ${ }^{2}$ Department of Pharmaceutical Sciences, Faculty of Science, Tshwane University of Technology, Pretoria, South Africa \\ ${ }^{3}$ SAMRC Herbal Drugs Research Unit, Faculty of Science, Tshwane University of Technology, Pretoria, South Africa
}

Correspondence should be addressed to Sandy van Vuuren; sandy.vanvuuren@wits.ac.za

Received 21 July 2016; Accepted 11 October 2016

Academic Editor: Fatih Demirci

Copyright ( 2016 Stephanie de Rapper et al. This is an open access article distributed under the Creative Commons Attribution License, which permits unrestricted use, distribution, and reproduction in any medium, provided the original work is properly cited.

\begin{abstract}
The paper focuses on the in vitro antimicrobial activity of Lavandula angustifolia Mill. (lavender) essential oil in combination with four commercial antimicrobial agents. Stock solutions of chloramphenicol, ciprofloxacin, nystatin, and fusidic acid were tested in combination with L. angustifolia essential oil. The antimicrobial activities of the combinations were investigated against the Gram-positive bacterial strain Staphylococcus aureus (ATCC 6538) and Gram-negative Pseudomonas aeruginosa (ATCC 27858) and Candida albicans (ATCC 10231) was selected to represent the yeasts. The antimicrobial effect was performed using the minimum inhibitory concentration (MIC) microdilution assay. Isobolograms were constructed for varying ratios. The most prominent interaction was noted when $L$. angustifolia essential oil was combined with chloramphenicol and tested against the pathogen P. aeruginosa ( $\Sigma$ FIC of 0.29). Lavendula angustifolia essential oil was shown in most cases to interact synergistically with conventional antimicrobials when combined in ratios where higher volumes of L. angustifolia essential oil were incorporated into the combination.
\end{abstract}

\section{Introduction}

The art of using essential oils for therapeutic practice has an extensive history reaching many continents around the world [1]. The practice of aromatherapy and the use of essential oils for therapeutic purposes has maintained its popularity through the ages and continued today with essential oils used as a popular alternate therapy for antimicrobial effects. The increased interest in aromatherapy for these purposes has launched essential oils into the international markets, where they are often sold as "natural antibiotics" $[2,3]$.

Lavendula angustifolia, considered the most versatile and popular of all essential oils used in aromatherapy, is well documented [4-8]. Within the field of aromatherapy, L. angustifolia essential oil is believed to have antimicrobial value for a plethora of conditions ranging from skin inflictions such as boils and yeast infections to respiratory complaints such as bronchitis and whooping cough [9-11]. The therapeutic use of L. angustifolia essential oil could be traced back to as early as Roman and Greek times, where it was frequently used medicinally due to the apparent lack of toxicity [11]. Lavandula species have also been proven in literature to have the potential to treat bacterial infections commonly associated with resistance to conventional antimicrobial agents. At a concentration of less than $1 \%, L$. angustifolia essential oil inhibits the growth of microorganisms such as methicillin-resistant Staphylococcus aureus and vancomycinresistant Enterococcus faecalis [12].

There have been a number of studies on the antimicrobial activities of essential oils in combination with conventional 
TABLE 1: The concentrations of essential oil and antimicrobial agent associated with the volume ratios studied.

\begin{tabular}{lccc}
\hline Plot number & $\begin{array}{c}\text { Volume ratio of essential } \\
\text { oil : antimicrobial agent } \\
\mu \mathrm{L}\end{array}$ & $\begin{array}{c}\text { Concentration of antimicrobial agent } \\
\text { in combination } \\
\mu \mathrm{g} / \mathrm{mL}\end{array}$ & $\begin{array}{c}\text { Concentration of essential oil in } \\
\text { combination } \\
\mathrm{mg} / \mathrm{mL}\end{array}$ \\
\hline 1 & $90: 10$ & 0.25 & 7.2 \\
2 & $80: 20$ & 0.50 & 6.4 \\
3 & $70: 30$ & 0.75 & 5.6 \\
4 & $60: 40$ & 1.00 & 4.8 \\
5 & $50: 50$ & 1.25 & 4.0 \\
6 & $40: 60$ & 1.50 & 3.2 \\
7 & $30: 70$ & 1.75 & 2.4 \\
9 & $20: 80$ & 2.00 & 1.6 \\
\end{tabular}

${ }^{*}$ Referring to points on isobologram graphs.

antibacterial agents [13-20]. A study conducted in 2014 aimed to identify the antimicrobial properties of 35 essential oil-antimicrobial combinations. The study investigated the effects of some popular essential oils such as lavender (Lavandula angustifolia) and tea-tree (Melaleuca alternifolia (Maiden \& Betche) Cheel.), and less popular oils such as cinnamon bark (Cinnamomum zeylanicum Blume) and marjoram (Origanum majorana L.) [21]. These oils were tested in combination with common $\beta$-lactam penicillin antibiotics and the structurally similar cephalosporins. Of the 35 combinations tested, only four were identified as synergistic. L. angustifolia essential oil in combination with piperacillin against Escherichia coli showed the greatest level of synergy with an EFIC value of 0.26 .

Despite the popularity and proven activity of L. angustifolia essential oil, no studies could be found that have focused on the antimicrobial potential of L. angustifolia essential oil in combination with non-beta lactam antimicrobial agents. With this in mind, the essential oil of L. angustifolia was investigated in combination with four commercially available antimicrobial agents (nystatin, chloramphenicol, ciprofloxacin, and fusidic acid) to determine what potential interaction may occur should they be used in combination.

\section{Materials and Methods}

The composition of L. angustifolia Mill. (Robertet ${ }^{\circledR}$ ) was confirmed using gas chromatography coupled to a mass spectrometer and flame ionization detector (GC-MS-FID). The GCMS-FID (Agilent 6890N GC system and 5973 MS) was equipped with a HP-Innowax polyethylene glycol column $(60 \mathrm{~m} \times 250 \mu \mathrm{m}$ i.d. $\times 0.25 \mu \mathrm{m}$ film thickness $)$. A volume of $1 \mu \mathrm{L}$ of the essential oil was injected (using a split ratio of $200: 1$ ) with an autosampler at 24.79 psi and an inlet temperature of $250^{\circ} \mathrm{C}$. The $\mathrm{GC}$ oven temperature was set at $60^{\circ} \mathrm{C}$ for 10 minutes and then $220^{\circ} \mathrm{C}$ at a rate of $4^{\circ} \mathrm{C} /$ minute for 10 minutes and followed by a temperature of $240^{\circ} \mathrm{C}$ at a rate of $1^{\circ} \mathrm{C} /$ minute. Helium was used as a carrier gas at a constant flow of $1.2 \mathrm{~mL} /$ minute. Spectra were obtained on electron impact at $70 \mathrm{eV}$, scanning from 35 to $550 \mathrm{~m} / \mathrm{z}$. The percentage composition of the individual components was quantified by integration measurements, using flame ionization detection (FID, $\left.250^{\circ} \mathrm{C}\right)$. Component identifications were made by comparing mass spectra from the total ion chromatogram and retention indices using NIST and Mass Finder GC-MS libraries.

For the antimicrobial analysis of L. angustifolia essential oil in combination with conventional antimicrobial agents, stock solutions of ciprofloxacin ( $\geq 98.0 \%$ purity, SigmaAldrich), nystatin (70.0\% purity, Sigma-Aldrich), and fusidic acid ( $\geq 98.0 \%$ purity, Sigma-Aldrich) were made up to a concentration of $0.01 \mathrm{mg} / \mathrm{mL}$ using sterile water as the diluent. A $70 \%$ ethanol solution was used initially as a solvent for chloramphenicol ( $\geq 98.0 \%$ purity, Sigma-Aldrich) and thereafter diluted in sterile water. These antimicrobial agents were selected for analysis due to their indication in respiratory and topical infections. Chloramphenicol was selected due to its indication in the treatment of serious Gramnegative bacterial infections [22]. Chloramphenicol was also investigated against $C$. albicans as it has been indicated in previous literature as having substantial antifungal activity [23]. Ciprofloxacin, a first-generation fluoroquinolone antibiotic, was selected due to its broad-spectrum activity. Fusidic acid was selected due to its specific use in the treatment of Gram-positive bacterial infections, while nystatin was chosen to represent the class of antifungal agents [22]. The oil of L. angustifolia was prepared to yield a stock concentration of $32 \mathrm{mg} / \mathrm{mL}$ in acetone. The following ratios (in $\mu \mathrm{L}$ ) of L. angustifolia essential oil and the antimicrobial agents under analysis were investigated (L. angustifolia essential oil: antimicrobial agent): $90: 10,80: 20,70: 30,60: 40,50: 50$, $40: 60,30: 70,20: 80$, and $10: 90$. For each ratio tested, the essential oil and antimicrobial concentration varied and the exact concentration for each ratio is given in Table 1 . The antimicrobial activities of the combinations were investigated against the Gram-positive bacterial strain Staphylococcus aureus (ATCC 6538) and Gram-negative strain Pseudomonas aeruginosa (ATCC 27858) and Candida albicans (ATCC 10231) was selected to represent the yeasts. The antimicrobial effect was determined by means of the minimum inhibitory 
concentration (MIC) microdilution assay [24]. The microtitre plates were prepared by adding $100 \mu \mathrm{L}$ of sterile, distilled water into each of the wells. The antimicrobial agents and L. angustifolia essential oil were added to the first row, at a volume of $100 \mu \mathrm{L}$ (where they were tested individually) and $50: 50 \mu \mathrm{L}$ (where they were tested in equal volume combinations). Negative controls (water/acetone) were included in each assay to determine the antimicrobial activity of the solvent. Sterile media, such as Tryptone Soya Broth (TSB), and culture controls were included to confirm sterility and viability, respectively. The Clinical and Laboratory Standards Institute (CLSI) [25] and KnowledgeBase [26] were used to compare antimicrobial break points of the MIC values obtained from antimicrobial testing. This is undertaken to ensure that the pathogen responded to the tested antimicrobial in a reproducible manner and that the MIC values were within the recommended ranges (Table 3). Cultures were added to all the wells of their respective microtitre plates, at a concentration of $1 \times 10^{6}$ colony forming units $(\mathrm{CFU}) / \mathrm{mL}$. The microtitre plates were incubated under optimal conditions of $37^{\circ} \mathrm{C}$ for 24 hours for bacteria and $37^{\circ} \mathrm{C}$ for 48 hours for the yeast. After incubation, $p$-iodonitrotetrazolium violet solution (INT) at a concentration of $0.4 \mathrm{mg} / \mathrm{mL}$ was added into each well ( $40 \mu \mathrm{L})$, upon which colour changes were noted approximately six hours later for the bacteria and 24 hours later for the yeast. The lowest concentration identified with no growth or colour change was determined as the MIC. The fractional inhibitory concentration (FIC) and the FIC index ( $\Sigma$ FIC) were calculated to determine the interaction between L. angustifolia essential oil and the selected antimicrobial agents. The $\Sigma F I C$ for each combination was interpreted as synergistic where $\Sigma$ FIC was less than or equal to 0.50 . For additive properties, $\Sigma$ FIC was interpreted as greater than 0.50 but less than or equal to 1.00. For indifference, $\Sigma F I C$ values are greater than 1.00 but less than or equal to 4.00 and antagonism occurs when $\Sigma$ FIC greater than 4.00 is observed [27].

For the varied concentrations of L. angustifolia essential oil, antibiotic combination, isobolograms were constructed using GraphPad Prism, version five ${ }^{\circledR}$ software to present the mean MIC values of the combinations as ratios [28]. The isobolograms were interpreted by examining the data points for each ratio in relation to the MIC values for the oils independently. All points between the $0.5: 0.5$ and $1.0: 1.0$ line were interpreted as additive and above the 1.0:1.0 line and below the $4.0: 4.0$ line were classified as noninteractive. The points below or on the $0.5: 0.5$ line on the isobologram were interpreted as synergistic with antagonism noted for data points above the $4.0: 4.0$ line [27]. All tests were undertaken in duplicate and when results differed by more than one dilution factor, a third replicate was undertaken.

\section{Results and Discussion}

The chemical composition of $L$. angustifolia essential oil was determined to confirm the specific chemotype (Table 2). A full chemical profile was established for this essential oil, with the major constituents, linalyl acetate (36.7\%), linalool (31.4\%), and terpinen-4-ol (14.9\%), identified. The chemical composition of L. angustifolia essential oil has been studied
TABle 2: The chemical composition of Lavandula angustifolia Mill. essential oil.

\begin{tabular}{|c|c|c|}
\hline RRI & Constituents & Percentage abundance \\
\hline 1016 & $\alpha$-Pinene & 0.1 \\
\hline 1019 & $\alpha$-Thujene & t.a. ${ }^{*}$ \\
\hline 1057 & Camphene & 0.1 \\
\hline 1104 & $\beta$-Pinene & t.a. ${ }^{*}$ \\
\hline 1159 & Myrcene & 0.2 \\
\hline 1193 & $\alpha$-Terpinene & t.a. ${ }^{*}$ \\
\hline 1194 & Limonene & 0.1 \\
\hline 1202 & Eucalyptol & 0.5 \\
\hline 1232 & $\beta$-trans-Ocimene & 3.0 \\
\hline 1242 & $\gamma$-Terpinene & 0.1 \\
\hline 1250 & $\beta$-cis-Ocimene & 2.1 \\
\hline 1319 & 3-Octanone & 0.4 \\
\hline 1270 & p-Cymene & 0.1 \\
\hline 1281 & Terpinolene & t.a. ${ }^{*}$ \\
\hline 1331 & Hexyl butyrate & 0.1 \\
\hline 1372 & Allo-ocimene & 0.5 \\
\hline 1376 & 1-Octenyl acetate & 0.8 \\
\hline 1385 & 3-Octanol & 0.1 \\
\hline 1411 & $n$-Hexyl butyrate & 0.3 \\
\hline 1441 & Hexyl-2-methylbutyrate & t.a. ${ }^{*}$ \\
\hline 1447 & cis-Linalool oxide & 0.2 \\
\hline 1471 & cis-Linalool oxide & 0.1 \\
\hline 1521 & Camphor & 0.3 \\
\hline 1541 & Linalool & $31.4^{\dagger}$ \\
\hline 1563 & Linalyl acetate & $36.7^{\dagger}$ \\
\hline 1572 & $\alpha$-Cedrene & t.a. ${ }^{*}$ \\
\hline 1573 & $\alpha$-Santalene & 0.4 \\
\hline 1584 & $\alpha$-Bergamotene & 0.3 \\
\hline 1602 & Terpinen-4-ol & $14.9^{\dagger}$ \\
\hline 1665 & $\beta$-Farnesene & 1.4 \\
\hline 1677 & Lavandulol & 1.2 \\
\hline 1680 & Cryptone & 0.2 \\
\hline 1701 & $\alpha$-Terpineol & 0.3 \\
\hline 1702 & Borneol & 0.7 \\
\hline 1741 & Carvone & t.a. ${ }^{*}$ \\
\hline 1763 & $\gamma$-Cadinene & 0.2 \\
\hline 1797 & Cuminaldehyde & 0.1 \\
\hline 1855 & p-Cymen-8-ol & 0.3 \\
\hline 2010 & Caryophyllene epoxide & t.a. ${ }^{*}$ \\
\hline \multirow[t]{2}{*}{2225} & Thymol & 0.1 \\
\hline & Total & $97.30 \%$ \\
\hline
\end{tabular}

${ }^{*}$ t.a. indicates trace amounts; $\dagger$ indicates major chemical constituents.

extensively in literature and the composition reported here is congruent with literature [29-32].

Initially, confirmation of the antimicrobial activity of the four antimicrobial agents was undertaken against the three test microorganisms (Table 3). Where possible, the MIC values determined were congruent with breakpoint expectations. Only $S$. aureus demonstrated a marginally higher 
TABLE 3: Mean MIC values in $\mu \mathrm{g} / \mathrm{mL}(n=3)$ for the antimicrobial agents selected for combination analysis.

\begin{tabular}{lcccccc}
\hline \multirow{2}{*}{$\begin{array}{l}\text { Antimicrobial agent } \\
\end{array}$} & \multicolumn{2}{c}{$\begin{array}{c}\text { C. albicans } \\
\text { ATCC 10231 }\end{array}$} & \multicolumn{2}{c}{$\begin{array}{c}\text { S. aureus } \\
\text { ATCC 6538 }\end{array}$} & \multicolumn{2}{c}{$\begin{array}{c}\text { P. aeruginosa } \\
\text { ATCC 27858 }\end{array}$} \\
& Value obtained & Break point range & Value obtained & Break point range & Value obtained & Break point range \\
\hline Chloramphenicol & 0.63 & $<4.00$ & 0.31 & $0.10-15.60$ & 0.31 & $0.06-32.00$ \\
Ciprofloxacin & $\mathrm{NA}^{\dagger}$ & $\mathrm{NA}$ & 0.11 & $0.12-0.50$ & 0.04 & $<1.00-2.50$ \\
Fusidic acid & $\mathrm{NA}$ & $\mathrm{NA}$ & 0.63 & $0.10->32.00$ & 0.31 & $\leq 1.00$ \\
Nystatin & 0.16 & $\leq 4.00$ & NA & NA & NA & NA \\
\hline
\end{tabular}

* Break point ranges for commercial antimicrobials as determined by the KnowledgeBase antimicrobial index, CLSI guidelines, and EUCAST antimicrobial index; ${ }^{\dagger} \mathrm{NA}$ : not applicable as microorganisms are not susceptible to these antimicrobial agents.

TABLE 4: The antimicrobial effect of the individual components within the essential oil : antimicrobial combination.

\begin{tabular}{|c|c|c|c|c|c|}
\hline \multirow[b]{2}{*}{ Microorganism } & \multicolumn{3}{|c|}{ MIC individual } & \multirow[b]{2}{*}{$\Sigma F I C$} & \multirow[b]{2}{*}{ Interpretation } \\
\hline & $\begin{array}{c}\mathrm{LA} \\
(\mathrm{mg} / \mathrm{mL})\end{array}$ & & & & \\
\hline \multirow{2}{*}{$\begin{array}{l}\text { C. albicans } \\
\text { (ATCC 10231) }\end{array}$} & \multirow{2}{*}{3.00} & $\mathrm{CH}$ & 0.63 & 1.00 & Additive \\
\hline & & $\mathrm{N}$ & 0.16 & 1.14 & Noninteractive \\
\hline \multirow{3}{*}{$\begin{array}{l}\text { S. aureus } \\
\text { (ATCC 6538) }\end{array}$} & \multirow{3}{*}{2.00} & $\mathrm{CH}$ & 0.31 & 0.75 & Additive \\
\hline & & $\mathrm{C}$ & 0.11 & 0.49 & Synergistic \\
\hline & & FA & 0.63 & 0.65 & Additive \\
\hline \multirow{3}{*}{$\begin{array}{l}\text { P. aeruginosa } \\
\text { (ATCC 27858) }\end{array}$} & \multirow{3}{*}{2.00} & $\mathrm{CH}$ & 0.31 & 0.29 & Synergistic \\
\hline & & $\mathrm{C}$ & 0.04 & 0.74 & Additive \\
\hline & & FA & 0.31 & 1.13 & Noninteractive \\
\hline
\end{tabular}

LA indicates L. angustifolia essential oil, $\mathrm{CH}$ indicates chloramphenicol, $\mathrm{N}$ indicates nystatin, $\mathrm{C}$ indicates ciprofloxacin, and FA indicates fusidic acid.

susceptibility pattern $(0.11 \mu \mathrm{g} / \mathrm{mL})$ than the expected range $(0.12-0.50 \mu \mathrm{g} / \mathrm{mL})$ for ciprofloxacin, but given that the assay is working with doubling dilutions, this is not significant.

The mean MIC values obtained for L. angustifolia essential oil against the tested pathogens were $3.00 \mathrm{mg} / \mathrm{mL}$, $2.00 \mathrm{mg} / \mathrm{mL}$, and $2.00 \mathrm{mg} / \mathrm{mL}$ for C. albicans, S. aureus, and $P$. aeruginosa, respectively. Synergy was noted for two interactions, $L$. angustifolia essential oil in combination with ciprofloxacin against $S$. aureus ( $\Sigma$ FIC of 0.49 ) and L. angustifolia essential oil in combination with chloramphenicol against $P$. aeruginosa ( $\Sigma$ FIC of 0.29) (Table 4). Before this study, no research has been conducted on the antimicrobial interaction between $L$. angustifolia essential oil and chloramphenicol, nor chloramphenicol in combination with other natural therapies against $P$. aeruginosa. Chloramphenicol has, however, been placed in combination with other essential oils and tested against other microorganisms. A study conducted in 2013 determined the antimicrobial effect of chloramphenicol in combination with Coriandrum sativum L. essential oil against Acinetobacter baumannii using the $\Sigma$ FIC analysis [33]. This combination also demonstrated considerable synergistic antimicrobial potential with a $\Sigma$ FIC value of 0.28 . The antimicrobial potential of this agent in combination with essential oil compounds is further augmented by a study conducted by Halawani [34]. According to Halawani [34], chloramphenicol in combination with thymoquinone and thymohydroquinone (the major chemical constituents of the essential oil Nigella sativa L.) demonstrated synergistic antimicrobial effects against E. coli, S. aureus, P. aeruginosa, and Salmonella typhimurium. These studies further demonstrate the antimicrobial potential of this antimicrobial agent in combination with essential oils.

In order to determine what interactions could be apparent when the concentration of oil and conventional antibiotic varies, further investigation was undertaken and plotted on isobolograms (Table 1, Figures 1-3). When investigating the combination of chloramphenicol and nystatin with $L$. angustifolia essential oil (Figure 1), synergy was noted for three of the nine ratios with chloramphenicol: L. angustifolia essential oil $(20: 80,30: 70$, and $40: 60)$ and one synergistic interaction (20:80) for nystatin: L. angustifolia essential oil. For the combination with chloramphenicol, synergy was more apparent where L. angustifolia essential oil was present in higher volume ratios. Indifference was mostly observed for the combinations of nystatin with L. angustifolia essential oil. Two ratios demonstrated antagonism (where nystatin is combined with $L$. angustifolia essential oil) at ratios of $20: 80$ and $30: 70$.

Against S. aureus, L. angustifolia essential oil was combined with the antimicrobial agents chloramphenicol, ciprofloxacin, and fusidic acid (Figure 2). Synergy was observed for the combination of chloramphenicol and $L$. angustifolia essential oil in four of the ratios investigated (chloramphenicol: L. angustifolia essential oil 10:90, 20:80, $30: 70$, and $40: 60$ ), with a predominantly additive relationship identified for the remainder of the other combinations 

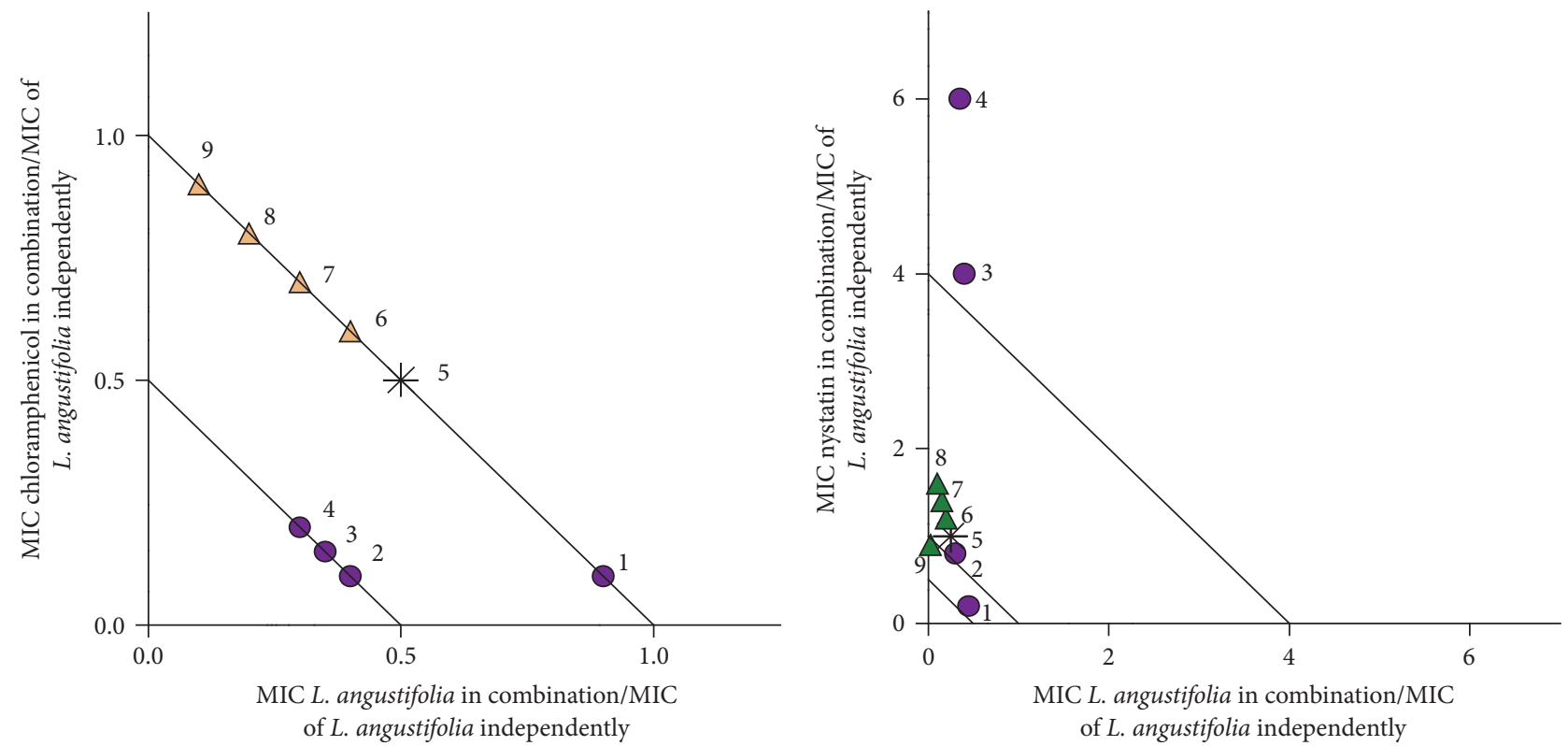

FIGURE 1: Isobologram representation of L. angustifolia essential oil in combination with chloramphenicol and nystatin at various ratios against C. albicans (ATCC 10231). - indicates L. angustifolia essential oil in majority volume, $\boldsymbol{\Delta}$ indicates the antimicrobial agent in majority volume, and $*$ indicates equal volume of $L$. angustifolia essential oil to antimicrobial agent. Points 1-9 (Table 1) provide exact concentrations for antimicrobial and lavender oil.

tested. When placed in combination with ciprofloxacin at varying ratios, five of the nine ratios investigated were identified as synergistic $(40: 60,50: 50,60: 40,70: 30$, and $20: 80)$. The combination of fusidic acid and L. angustifolia essential oil varied between additive and synergistic, depending on the ratio. Synergy was observed for three of the ratios investigated $(10: 90,20: 80$, and $30: 70)$.

When investigated against $P$. aeruginosa, the L. angustifolia essential oil combinations with chloramphenicol, ciprofloxacin, and fusidic acid demonstrated varied interactions (Figure 3). Mainly synergistic antimicrobial interactions occurred with six of the nine ratios investigated for the combination of L. angustifolia essential oil with chloramphenicol. When placed in combination with ciprofloxacin, additive effects were predominant. Similarly, the combination of fusidic acid and L. angustifolia essential oil in various combinations demonstrated mainly additive interactions, with synergy identified for one ratio $(20: 80)$.

Potentiation of an antimicrobial agent results when a technique is applied to the antimicrobial agent causing it to demonstrate a greater antimicrobial effect at a lower concentration [35]. A number of studies have been conducted on the potential of plants to potentiate antimicrobial agents [36-45]. One study determined that Rosmarinus officinalis L. essential oil potentiates the antimicrobial activity of erythromycin 1632-fold against $S$. aureus [40].

The most promising combination is noted for L. angustifolia essential oil with fusidic acid against $S$. aureus in which the antimicrobial effect of this agent is potentiated 5 -fold. Fusidic acid is primarily applied in the treatment of topical Staphylococcal infections; therefore the potentiation of this antimicrobial agent suggests promise for the use of this combination within future pharmaceutical preparations.

When combined with chloramphenicol, it was noted that ratios higher in L. angustifolia essential oil were responsible for the synergistic antimicrobial effects of the combination; however, an antagonistic interaction was observed with the combination of nystatin and L. angustifolia essential oil. This demonstrates that, in spite of the positive results obtained against some pathogens, caution should still be exercised. The safety of combining complementary therapy and conventional prescription medications has been of concern [46]. A study conducted by Van Vuuren et al. [47] substantiates this point as the combination of $M$. alternifolia essential oil and ciprofloxacin against the microorganism $S$. aureus was shown to yield an antagonistic antimicrobial effect with $\Sigma$ FIC values ranging from 5.17 to 7.70 , dependant on the concentration at which these agents were combined.

Ciprofloxacin is indicated in the treatment of many bacterial infections including $S$. aureus related infections [22], while L. angustifolia essential oil is indicated mainly for the treatment of superficial skin infections, many of which originate from a Staphylococcal source [9-11]. Interestingly, this combination showed that L. angustifolia essential oil potentiated the antimicrobial effects of ciprofloxacin suggesting some therapeutic benefit in combining these agents. When investigated against $P$. aeruginosa, L. angustifolia essential oil was placed in combination with chloramphenicol, ciprofloxacin, and fusidic acid.

The outcomes obtained indicate that L. angustifolia essential oil has the potential to improve the antibacterial effects of some commercial antibiotics. This may be as a result of the 

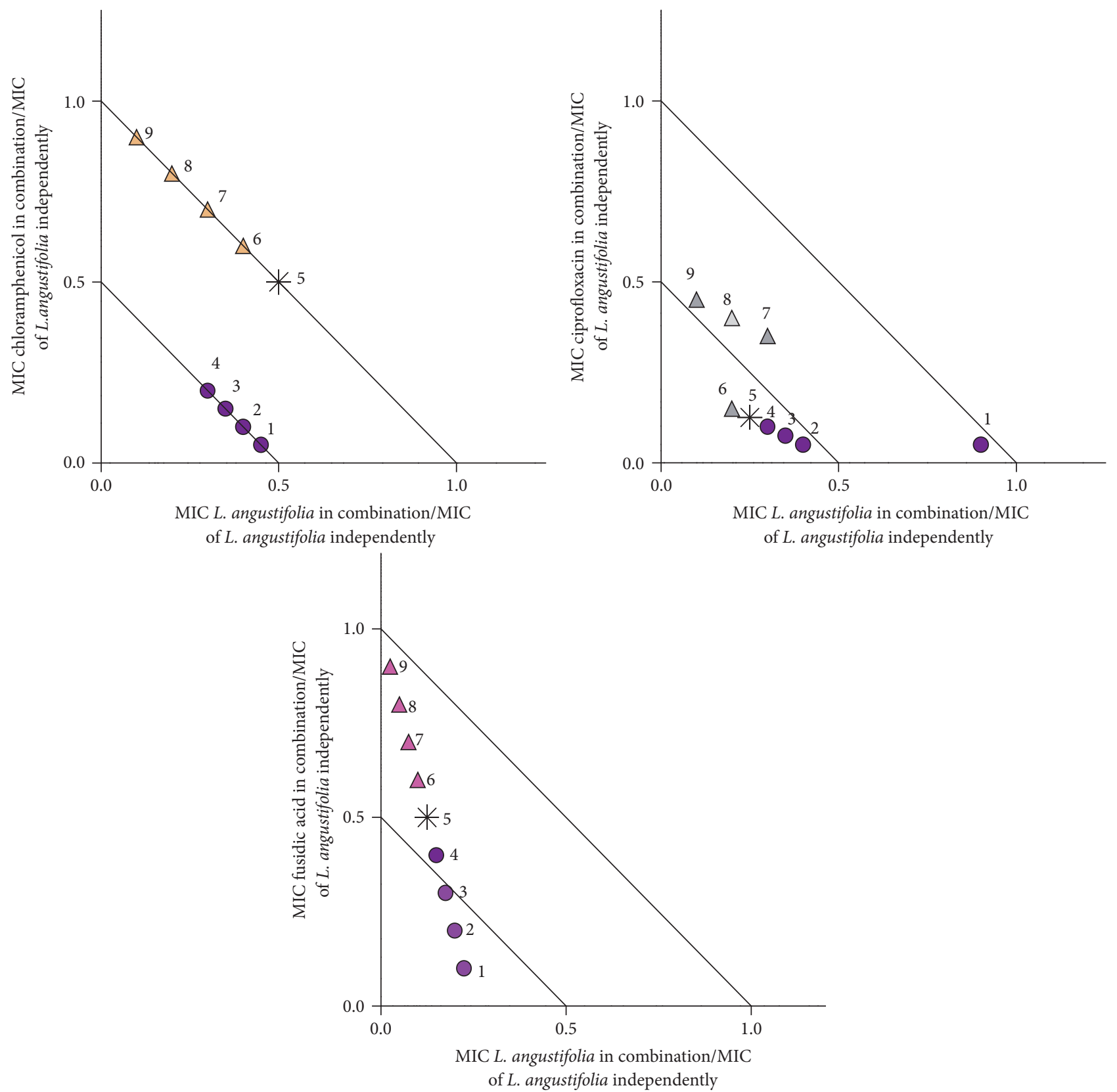

FIGURE 2: Isobologram representation of L. angustifolia essential oil in combination with chloramphenicol, ciprofloxacin, and fusidic acid at various ratios against $S$. aureus (ATCC 6538). - indicates $L$. angustifolia essential oil in majority volume, $\mathbf{\Delta}$ indicates the antimicrobial agent in majority volume, and $*$ indicates equal volume of $L$. angustifolia essential oil to antimicrobial agent. Points 1-9 (Table 1) provide exact concentrations for antimicrobial and lavender oil.

interactions occurring between the chemical compounds of L. angustifolia essential oil and the antimicrobial agents used. Due to the complexity of essential oil chemistry it has been determined that essential oils have the ability to affect any number of antimicrobial pathways. Studies on the effects of the major chemical constituents of L. angustifolia essential oil, linalool, linalyl acetate, and terpinen-4-ol, indicate the mechanism of action of these components to comprise mainly of damage to the lipid layer of the cell membrane, resulting in bacterial cell leakage [48-50]. Although some individual chemical compounds have been determined as having antimicrobial potential independently, the effects of the essential oils are predominantly due to the interactions of the chemical entities [51]. The antimicrobial agent most potentiated by L. angustifolia essential oil was fusidic acid. Fusidic acid causes damage to bacterial cells by reducing protein synthesis [22]. The combination of L. angustifolia essential oil and fusidic acid highlights the potential of multitarget effects between essential oils and their chemistry when used in combination with conventional antimicrobial agents. 

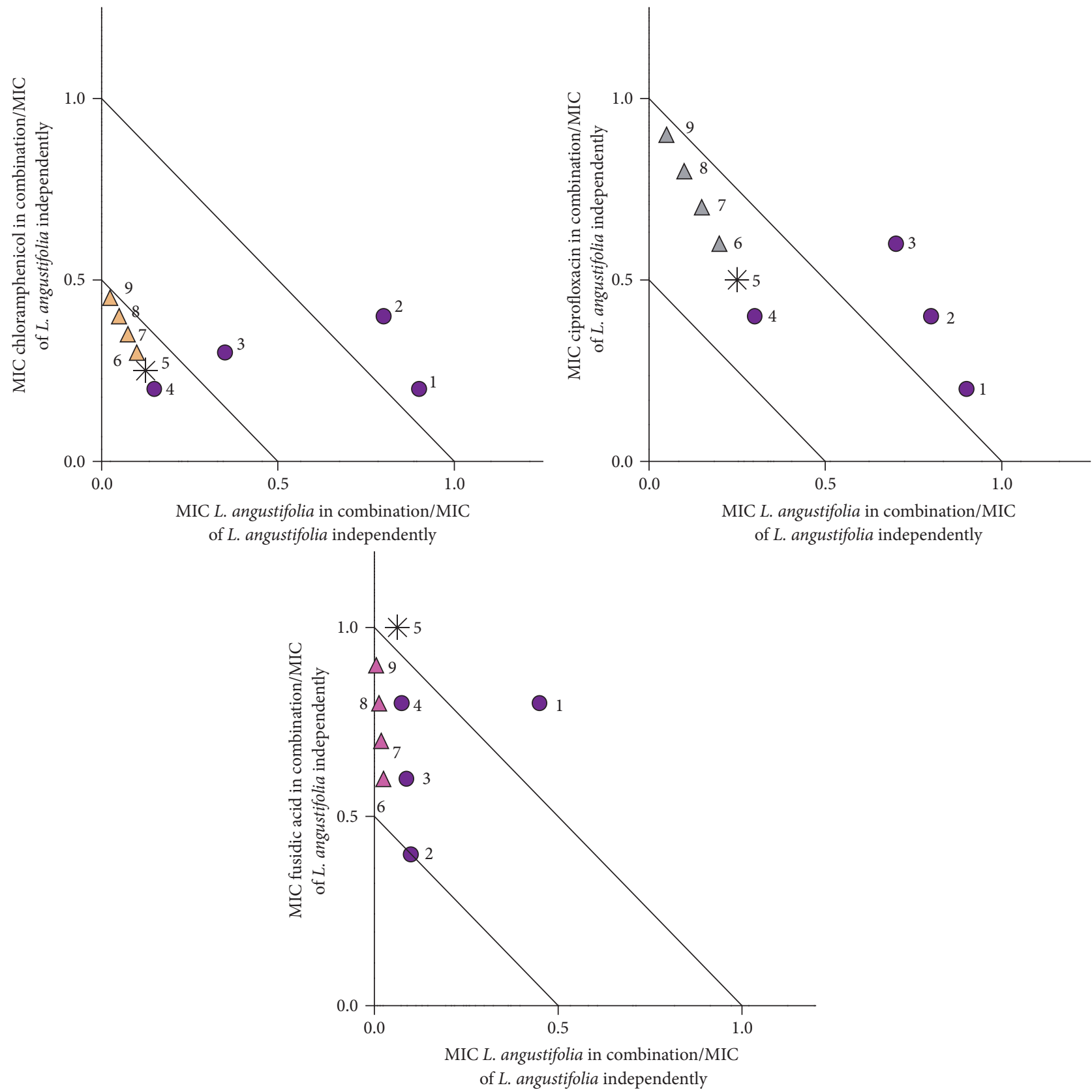

FIGURE 3: Isobologram representation of L. angustifolia essential oil in combination with chloramphenicol, ciprofloxacin, and fusidic acid at various ratios against $P$. aeruginosa (ATCC 27858). - indicates $L$. angustifolia essential oil in majority volume, $\mathbf{\Delta}$ indicates the antimicrobial agent in majority volume, and $*$ indicates equal volume of $L$. angustifolia essential oil to antimicrobial agent. Points 1-9 (Table 1) provide exact concentrations for antimicrobial and lavender oil.

In order for antimicrobial resistance to be overcome, such a mechanism is required in proposed combinations in order to render a greater antimicrobial effect [52]. This interaction is further observed amongst the combinations eliciting additive and synergistic effects such as L. angustifolia essential oil in combination with ciprofloxacin (inhibiting DNA enzymes [22]) and L. angustifolia essential oil in combination with chloramphenicol (inhibiting protein synthesis [22]). One needs to remain cognisant that synergistic interactions may not necessarily be as a result of the major compounds (only) but minor compounds may also play a role in the positive interactions observed.

\section{Conclusion}

Antimicrobial resistance has been on the rise over recent years with an unknown number of resistant bacterial strains developed. The microorganism Enterococcus faecium, responsible for causing infections such as endocarditis, cellulitis, and bacteremia [22], had, as of 2009, developed a high 
level of resistance to aminoglycoside antibiotics. No known alternative for treatment currently exists [53]. Due to this growing level of resistance, research has been undertaken to develop new products with antimicrobial potential for use independently and in combination with current antibiotics, with researchers looking towards natural products and plants for solutions [54]. The lack of antagonism and indication of possible drug potentiation within this study further augments the potential for the use of essential oils in combination with antimicrobial agents for a synergistic antimicrobial effect. This study suggests some therapeutic potential in combining L. angustifolia essential oil with common antimicrobial agents in the future.

\section{Competing Interests}

The authors declare no conflict of interests.

\section{Acknowledgments}

The authors thank the National Research Foundation for their generous contribution towards bursary funding. They appreciate the assistance of Dr. Guy Kamatou with the analysis of the essential oil which was kindly supplied by Robertet (France).

\section{References}

[1] J. Buckle, Clinical Aromatherapy: Essential Oils in Practice, Churchill Livingstone, LDN, 2nd edition, 2003.

[2] P. Hili, The Antimicrobial Properties of Essential Oils, Winter Press, KNT, 2001.

[3] S. F. van Vuuren, "Antimicrobial activity of South African medicinal plants," Journal of Ethnopharmacology, vol. 119, no. 3, pp. 462-472, 2008.

[4] M. Grieve, A Modern Herbal, Harcourt, Brace \& Co, New York, NY, USA, 1931.

[5] R. M. Gattefosse, Gattefosse's Aromatherapy, Ebury Publishing, Saffron Walden, UK, 1937.

[6] S. Cassella, J. P. Cassella, and I. Smith, "Synergistic antifungal activity of tea tree (Melaleuca alternifolia) and lavender (Lavandula angustifolia) essential oils against dermatophyte infection," International Journal of Aromatherapy, vol. 12, no. 1, pp. 2-15, 2002.

[7] H. M. A. Cavanagh and J. M. Wilkinson, "Biological activities of lavender essential oil," Phytotherapy Research, vol. 16, no. 4, pp. 301-308, 2002.

[8] C.-M. Saviuc, V. Drumea, L. Olariu, M.-C. Chifiriuc, E. Bezirtzoglou, and V. Lazăr, "Essential oils with microbicidal and antibiofilm activity," Current Pharmaceutical Biotechnology, vol. 16, no. 2, pp. 137-151, 2015.

[9] W. Sellar, The Directory of Essential Oils, C.W. Daniel Company Limited, LDN, 1992.

[10] J. Lawless, The Illustrated Encyclopedia of Essential Oils: The Complete Guide to the use of oils in Aromatherapy and Herbalism, Element Books Limited, Rockport, Mass, USA, 1995.

[11] S. Curtis, Essential Oils, Aurum Press, LDN, 1996.

[12] R. R. S. Nelson, "In-vitro activities of five plant essential oils against methicillin-resistant Staphylococcus aureus and vancomycin-resistant Enterococcus faecium," Journal of Antimicrobial Chemotherapy, vol. 40, no. 2, pp. 305-306, 1997.

[13] E. L. Avenirova, I. P. Ashmarin, N. A. Movchan, and I. K. Lapina, "Combination of novoimanine with antibiotics with a different mechanism of action," Antibiotiki, vol. 20, no. 7, pp. 636-639, 1975.

[14] B. Suresha, S. Sriram, S. A. Dhanaraj, K. Elango, and K. Chinnaswamy, "Anticandidal activity of Santolina chamaecyparissus volatile oil," Journal of Ethnopharmacology, vol. 55, no. 2, pp. 151159, 1997.

[15] S. Shiota, M. Shimizu, T. Mizusima et al., "Restoration of effectiveness of $\beta$-lactams on methicillin-resistant Staphylococcus aureus by tellimagrandin I from rose red," FEMS Microbiology Letters, vol. 185, no. 2, pp. 135-138, 2000.

[16] S. Shin and C.-A. Kang, "Antifungal activity of the essential oil of Agastache rugosa Kuntze and its synergism with ketoconazole," Letters in Applied Microbiology, vol. 36, no. 2, pp. 111-115, 2003.

[17] R. Giordani, J. Trebaux, M. Masi, and P. Regli, "Enhanced antifungal activity of ketoconazole by Euphorbia characias latex against Candida albicans," Journal of Ethnopharmacology, vol. 78, no. 1, pp. 1-5, 2001.

[18] S. Hemaiswarya, A. K. Kruthiventi, and M. Doble, "Synergism between natural products and antibiotics against infectious diseases," Phytomedicine, vol. 15, no. 8, pp. 639-652, 2008.

[19] V. Lorenzi, A. Muselli, A. F. Bernardini et al., "Geraniol restores antibiotic activities against multidrug-resistant isolates from gram-negative species," Antimicrobial Agents and Chemotherapy, vol. 53, no. 5, pp. 2209-2211, 2009.

[20] M. Fadli, J. Chevalier, A. Saad, N.-E. Mezrioui, L. Hassani, and J.-M. Pages, "Essential oils from Moroccan plants as potential chemosensitisers restoring antibiotic activity in resistant Gramnegative bacteria," International Journal of Antimicrobial Agents, vol. 38, no. 4, pp. 325-330, 2011.

[21] P. S. X. Yap, S. H. E. Lim, C. P. Hu, and B. C. Yiap, "Combination of essential oils and antibiotics reduce antibiotic resistance in plasmid-conferred multidrug resistant bacteria," Phytomedicine, vol. 20, no. 8-9, pp. 710-713, 2013.

[22] M. H. Beers, R. S. Porter, T. V. Jones, J. L. Kaplan, and M. Berkwits, The Merck Manual of Diagnosis and Therapy, Merck Research Laboratories, Rahway, NJ, USA, 18th edition, 2006.

[23] W. Logemann, L. Almirante, S. Galimberti, and I. De Carneri, "Influence of dichloroacetylation on the antimicrobial activity of chloramphenicol derivatives and of various amines," British Journal of Pharmacology and Chemotherapy, vol. 17, pp. 286296, 1961.

[24] S. de Rapper, S. F. Van Vuuren, G. P. P. Kamatou, A. M. Viljoen, and E. Dagne, "The additive and synergistic antimicrobial effects of select frankincense and myrrh oils-a combination from the pharaonic pharmacopoeia," Letters in Applied Microbiology, vol. 54, no. 4, pp. 352-358, 2012.

[25] Clinical Laboratory and Science Institute (CLSI), Methods for Dilution Antimicrobial Susceptibility Tests for Bacteria That Grow Aerobically. Approved Standard M7-A6, National Committee for Clinical Laboratory Standards, Wayne, Pa, USA, 6th edition, 2003.

[26] KnowledgeBase, "KnowledgeBase: The antimicrobial index," http://antibiotics.toku-e.com/.

[27] S. van Vuuren and A. Viljoen, "Plant-based antimicrobial studies-methods and approaches to study the interaction between natural products," Planta Medica, vol. 77, no. 11, pp. 1168-1182, 2011. 
[28] S. Suliman, S. F. van Vuuren, and A. M. Viljoen, "Validating the in vitro antimicrobial activity of Artemisia afra in polyherbal combinations to treat respiratory infections," South African Journal of Botany, vol. 76, no. 4, pp. 655-661, 2010.

[29] D. J. Daferera, B. N. Ziogas, and M. G. Polissiou, "GC-MS analysis of essential oils from some Greek aromatic plants and their fungitoxicity on Penicillium digitatum," Journal of Agricultural and Food Chemistry, vol. 48, no. 6, pp. 2576-2581, 2000.

[30] S. Behnam, M. Farzaneh, M. Ahmadzadeh, and A. S. Tehrani, "Composition and antifungal activity of essential oils of Mentha piperita and Lavandula angustifolia on post-harvest phytopathogens," Communications in Agricultural and Applied Biological Sciences, vol. 71, no. 3, pp. 1321-1326, 2006.

[31] S. Roller, N. Ernest, and J. Buckle, "The antimicrobial activity of high-necrodane and other lavender oils on methicillin-sensitive and -resistant Staphylococcus aureus (MSSA and MRSA)," Journal of Alternative and Complementary Medicine, vol. 15, no. 3, pp. 275-279, 2009.

[32] M. Soković, J. Glamočlija, P. D. Marin, D. Brkić, and L. J. L. D. van Griensven, "Antibacterial effects of the essential oils of commonly consumed medicinal herbs using an in vitro model," Molecules, vol. 15, no. 11, pp. 7532-7546, 2010.

[33] A. Duarte, S. Ferreira, F. Silva, and F. C. Domingues, "Synergistic activity of coriander oil and conventional antibiotics against Acinetobacter baumannii," Phytomedicine, vol. 19, no. 3-4, pp. 236-238, 2012.

[34] E. Halawani, "Antibacterial activity of thymoquinone and thymohydroquinone of Nigella sativa L. and their interaction with some antibiotics," Advanced Biomedical Research, vol. 3, pp. 148152, 2009.

[35] J. H. Hare, "Antibiotic potentiation-a review," Canadian Journal of Comparative Medicine and Veterinary Science, vol. 24, pp. 171-176, 1960.

[36] W.-H. Zhao, Z.-Q. Hu, S. Okubo, Y. Hara, and T. Shimamura, "Mechanism of synergy between epigallocatechin gallate and $\beta$-lactams against methicillin-resistant Staphylococcus aureus," Antimicrobial Agents and Chemotherapy, vol. 45, no. 6, pp. 17371742, 2001.

[37] Z.-Q. Hu, W.-H. Zhao, N. Asano, Y. Yoda, Y. Hara, and T. Shimamura, "Epigallocatechin gallate synergistically enhances the activity of carbapenems against methicillin-resistant Staphylococcus aureus," Antimicrobial Agents and Chemotherapy, vol. 46, no. 2, pp. 558-560, 2002.

[38] S. Gibbons, M. Oluwatuyi, N. C. Veitch, and A. I. Gray, "Bacterial resistance modifying agents from Lycopus europaeus," Phytochemistry, vol. 62, no. 1, pp. 83-87, 2003.

[39] S. Gibbons, E. Moser, and G. W. Kaatz, "Catechin gallates inhibit multidrug resistance (MDR) in Staphylococcus aureus," Planta Medica, vol. 70, no. 12, pp. 1240-1242, 2004.

[40] M. Oluwatuyi, G. W. Kaatz, and S. Gibbons, "Antibacterial and resistance modifying activity of Rosmarinus officinalis," Phytochemistry, vol. 65, no. 24, pp. 3249-3254, 2004.

[41] P. D. Stapleton, S. Shah, J. C. Anderson, Y. Hara, J. M. T. Hamilton-Miller, and P. W. Taylor, "Modulation of $\beta$-lactam resistance in Staphylococcus aureus by catechins and gallates," International Journal of Antimicrobial Agents, vol. 23, no. 5, pp. 462-467, 2004.

[42] H. Shibata, K. Kondo, R. Katsuyama et al., "Alkyl gallates, intensifiers of $\beta$-lactam susceptibility in methicillin-resistant Staphylococcus aureus," Antimicrobial Agents and Chemotherapy, vol. 49, no. 2, pp. 549-555, 2005.
[43] B. Marquez, L. Neuville, N. J. Moreau et al., "Multidrug resistance reversal agent from Jatropha elliptica," Phytochemistry, vol. 66, no. 15, pp. 1804-1811, 2005.

[44] N. Al-hebshi, M. Al-haroni, and N. Skaug, "In vitro antimicrobial and resistance-modifying activities of aqueous crude khat extracts against oral microorganisms," Archives of Oral Biology, vol. 51, no. 3, pp. 183-188, 2006.

[45] E. C. J. Smith, E. M. Williamson, N. Wareham, G. W. Kaatz, and S. Gibbons, "Antibacterials and modulators of bacterial resistance from the immature cones of Chamaecyparis lawsoniana," Phytochemistry, vol. 68, no. 2, pp. 210-217, 2007.

[46] Z. Hübsch, R. L. Van Zyl, I. E. Cock, and S. F. van Vuuren, "Interactive antimicrobial and toxicity profiles of conventional antimicrobials with Southern african medicinal plants," South African Journal of Botany, vol. 93, pp. 185-197, 2014.

[47] S. F. Van Vuuren, S. Suliman, and A. M. Viljoen, "The antimicrobial activity of four commercial essential oils in combination with conventional antimicrobials," Letters in Applied Microbiology, vol. 48, no. 4, pp. 440-446, 2009.

[48] C. F. Carson, B. J. Mee, and T. V. Riley, "Mechanism of action of Melaleuca alternifolia (Tea Tree) oil on Staphylococcus aureus determined by time-kill, lysis, leakage, and salt tolerance assays and electron microscopy," Antimicrobial Agents and Chemotherapy, vol. 46, no. 6, pp. 1914-1920, 2002.

[49] D. Trombetta, F. Castelli, M. G. Sarpietro et al., "Mechanisms of antibacterial action of three monoterpenes," Antimicrobial Agents and Chemotherapy, vol. 49, no. 6, pp. 2474-2478, 2005.

[50] J. C. Lopez-Romero, H. González-Ríos, A. Borges, and M. Simões, "Antibacterial effects and mode of action of selected essential oils components against Escherichia coli and Staphylococcus aureus," Evidence-Based Complementary and Alternative Medicine, vol. 2015, Article ID 795435, 9 pages, 2015.

[51] M. Hyldgaard, T. Mygind, and R. L. Meyer, "Essential oils in food preservation: mode of action, synergies, and interactions with food matrix components," Frontiers in Microbiology, vol. 3, article 12, 2012.

[52] W. T. Langeveld, E. J. Veldhuizen, and S. A. Burt, "Synergy between essential oil components and antibiotics: a review," Critical Reviews in Microbiology, vol. 40, no. 1, pp. 76-94, 2013.

[53] C. A. Arias and B. E. Murray, "Antibiotic-resistant bugs in the 21st century-a clinical super-challenge," New England Journal of Medicine, vol. 360, no. 5, pp. 439-443, 2009.

[54] M. Othman, H. S. Loh, C. Wiart, T. J. Rhoo, K. H. Lim, and K. N. Ting, "Optimal methods for evaluating antimicrobial activities from plant extracts," Journal of Microbiological Methods, vol. 80, pp. 161-166, 2011. 


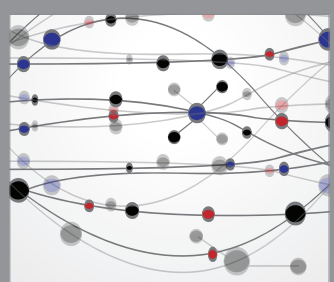

The Scientific World Journal
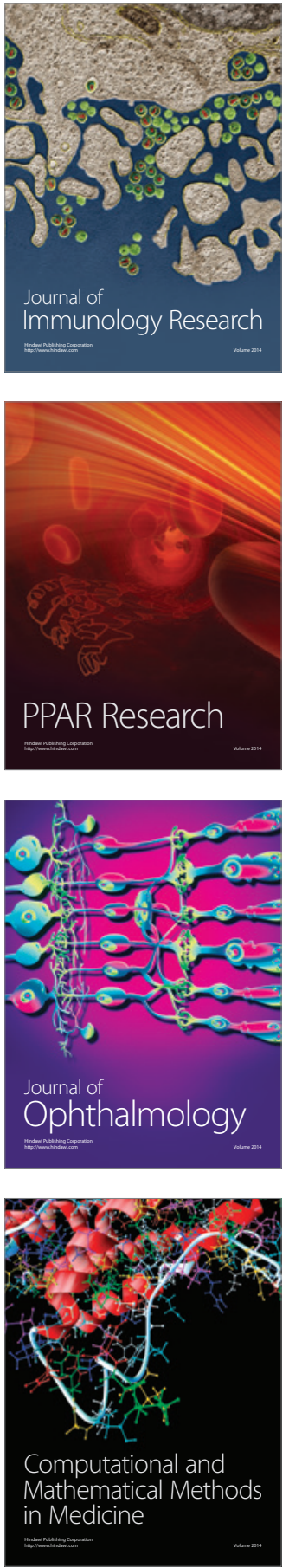

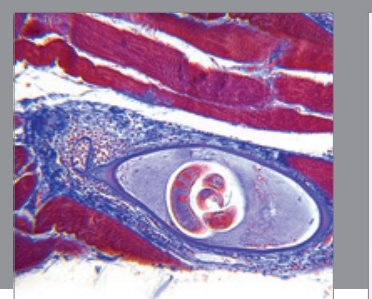

Gastroenterology Research and Practice

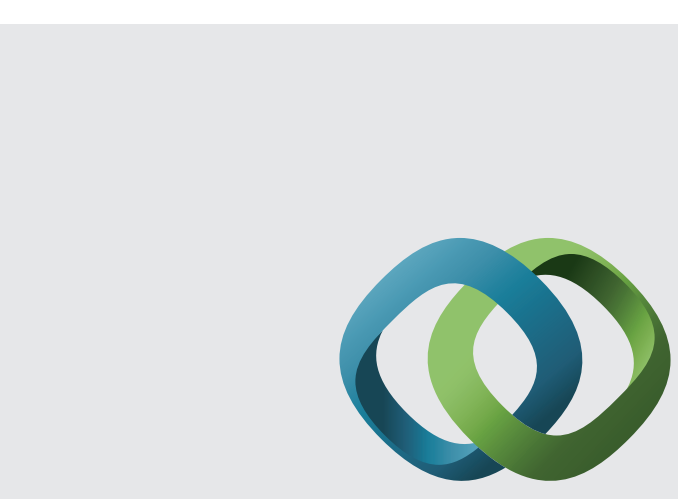

\section{Hindawi}

Submit your manuscripts at

http://www.hindawi.com
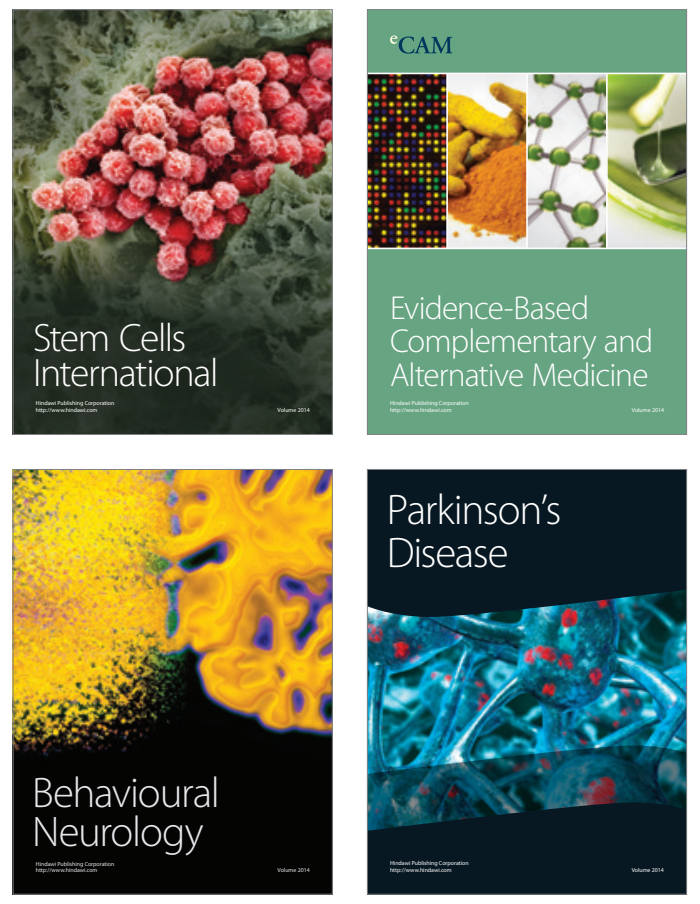
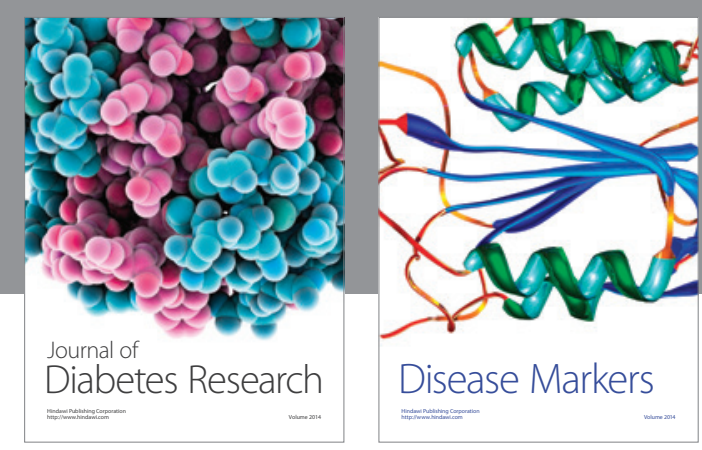

Disease Markers
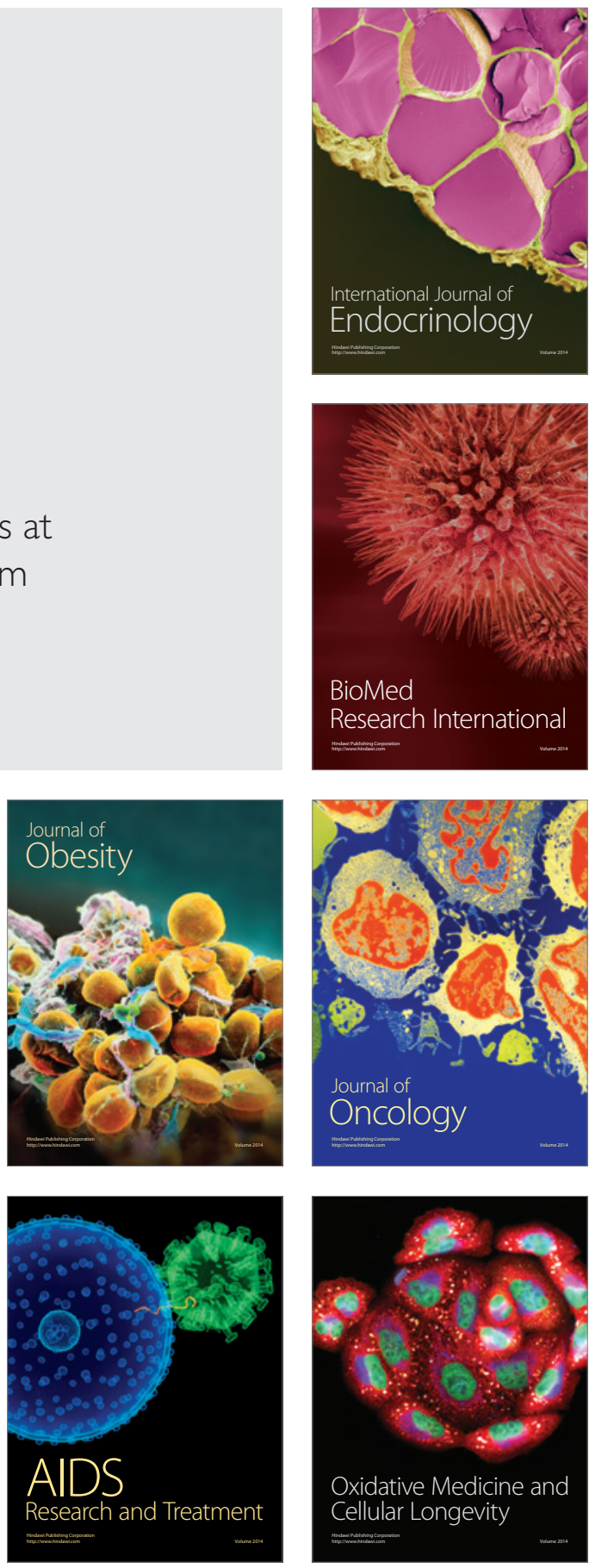